\title{
Clozapine-Induced Seizures and EEG Changes: A Case Report and Discussion of Clinical Management
}

\author{
Jeffrey Daly, M.D. \\ Butler Hospital, Rhode Island, Providence \\ Stephen Salloway, M.D., M.S. \\ Butler Hospital, Rhode Island, Providence
}

Follow this and additional works at: https://jdc.jefferson.edu/jeffjpsychiatry

Part of the Psychiatry Commons

Let us know how access to this document benefits you

\section{Recommended Citation}

Daly, M.D., Jeffrey and Salloway, M.D., M.S., Stephen (1993) "Clozapine-Induced Seizures and EEG

Changes: A Case Report and Discussion of Clinical Management," Jefferson Journal of Psychiatry. Vol. 11

: Iss. 1 , Article 8.

DOI: https://doi.org/10.29046/JJP.011.1.011

Available at: https://jdc.jefferson.edu/jeffjpsychiatry/vol11/iss1/8

This Article is brought to you for free and open access by the Jefferson Digital Commons. The Jefferson Digital Commons is a service of Thomas Jefferson University's Center for Teaching and Learning (CTL). The Commons is a showcase for Jefferson books and journals, peer-reviewed scholarly publications, unique historical collections from the University archives, and teaching tools. The Jefferson Digital Commons allows researchers and interested readers anywhere in the world to learn about and keep up to date with Jefferson scholarship. This article has been accepted for inclusion in Jefferson Journal of Psychiatry by an authorized administrator of the Jefferson Digital Commons. For more information, please contact: JeffersonDigitalCommons@jefferson.edu. 


\title{
Clozapine-Induced Seizures and EEG Changes A Case Report and Discussion of Clinical Management
}

\author{
Jeffrey Daly M.D. \\ Stephen Salloway M.D., M.S.
}

\begin{abstract}
Clozapine is an atypical antipsychotic agent associated with a higher frequency of seizures than standard neuroleptics. In addition, clozapine causes epileptiform abnormalities in the EEG in up to $72 \%$ of patients. A patient who developed a generalized seizure shortly after beginning clozapine treatment and the patient's EEG findings are presented. The neuropharmacology of clozapine and the management of clozapine-induced seizures and EEG abnormalities are discussed.

Clozapine (Clozaril) is a unique antipsychotic which has been shown to be effective in the treatment of refractory schizophenia $(1,2)$. Compared with standard neuroleptics clozapine has minimal extrapyramidal side effects and poses a low risk for tardive dyskinesia $(1,3,4,5,6)$.

Developed in 1960, clozapine was delayed from earlier widespread use by its side effect profile. The most dangerous of the common side effects is agranulocytosis, which has been reported in $1 \%$ to $2 \%$ of cases (7). Other adverse effects include hypotension, fatigue, drug fever, pharmacogenic delirium, tachycardia, and seizures. Associated seizures have been found in $4 \%$ of U.S. cases (7) compared to $1 \%$ to $2 \%$ in standard neuroleptics (8). Data from the manufacturer, Sandoz, indicates that these seizures are dose dependent with patients treated with 600 to $900 \mathrm{mg} /$ day having a seizure frequency of $5 \%$; those treated with 300 to $599 \mathrm{mg} /$ day, 3-4\%; and those patients treated with less than $300 \mathrm{mg}$ /day having a seizure frequency of $1-2 \%$ (9). A similar dose dependent frequency was found by Devinsky et al, who also suggest that rapid upward titration of clozapine may increase seizure risk (10).

EEG abnormalities have been noted in $72 \%$ of patients on clozapine (11). The EEG typically shows slow waves and paroxysmal discharges which may appear to be epileptiform. As clozapine use increases, the issue of how to manage clozapineinduced seizures and EEG changes becomes an important clinical problem.

In this report we present the case of a patient who had a seizure while on a low dose of clozapine and an abnormal EEG which persisted for weeks after her last seizure. This is followed by a discussion of the unique properties of clozapine which
\end{abstract}


may contribute to its increased seizure frequency, its effect on EEG's, and a review of current guidelines in the clinical management of clozapine-induced seizures.

\section{CASE REPORT}

Ms. B. is a 64 year old white female, group home resident, with no medical problems who has a 40 year history of chronic undifferentiated schizophrenia. Her psychosis and disorganized behavior had been refractory to electroconvulsive therapy and trials of multiple neuroleptics. The patient was most recently on haloperidol and lithium when she developed a severe dystonic reaction. These medications were discontinued and treatment with clozapine was initiated as an outpatient. An initial dose of $25 \mathrm{mg} /$ day was increased $25 \mathrm{mg}$ every two days. On day 14 of clozapine treatment, at a dose of $175 \mathrm{mg} /$ day, the patient had a witnessed generalized tonic-clonic seizure. At this time she fell to the floor, had clonic movements of all extremities lasting approximately two minutes then became flaccid and unresponsive for another two minutes. Upon regaining consciousness she experienced a one hour period of confusion and disorientation. The patient had no history of seizures, head trauma, or substance abuse. She had no known medical conditions or recent medication changes other then starting clozapine which put her at increased risk for a seizure. No additional generalized seizures were noted. The group home treatment team did not seek immediate medical consultation and continued clozapine treatment at a dose of $175 \mathrm{mg} /$ day. Her behavior remained disorganized for seven days after the seizure and she was admitted to the psychiatric hospital for evaluation of her prolonged change in mental status.

Neurologic exam revealed psychomotor retardation and confusion without focal sensory or motor findings and the remainder of the physical exam was unremarkable. Metabolic, toxicology, endocrine, infectious and hematological screens as well as a head CT were unremarkable. Initial EEG obtained nine days after the witnessed seizure, with the patient still on clozapine, showed beta rhythms in the background secondary to treatment with benzodiazepines and brief runs of diffuse high voltage slow and sharp wave paroxysmal discharges as shown in Figure 1.

Due to concern about her prolonged encephalopathy clozapine was discontinued and the patient was started on carbamazepine. The authors were called in for neurological consultation at this time. Follow-up EEG 15 days after stopping the clozapine showed resolution of epileptiform activity.

\section{DISCUSSION}

Dopamine Receptors and Clozapine Action

A great deal of information about dopamine receptor subtypes has recently become available which should shed light on clozapine's antipsychotic and proconvulsant effects. Dopamine receptors are glycoprotein molecules, located on pre-synaptic and post-synaptic membranes and found primarily in the striatum, cortex and limbic 


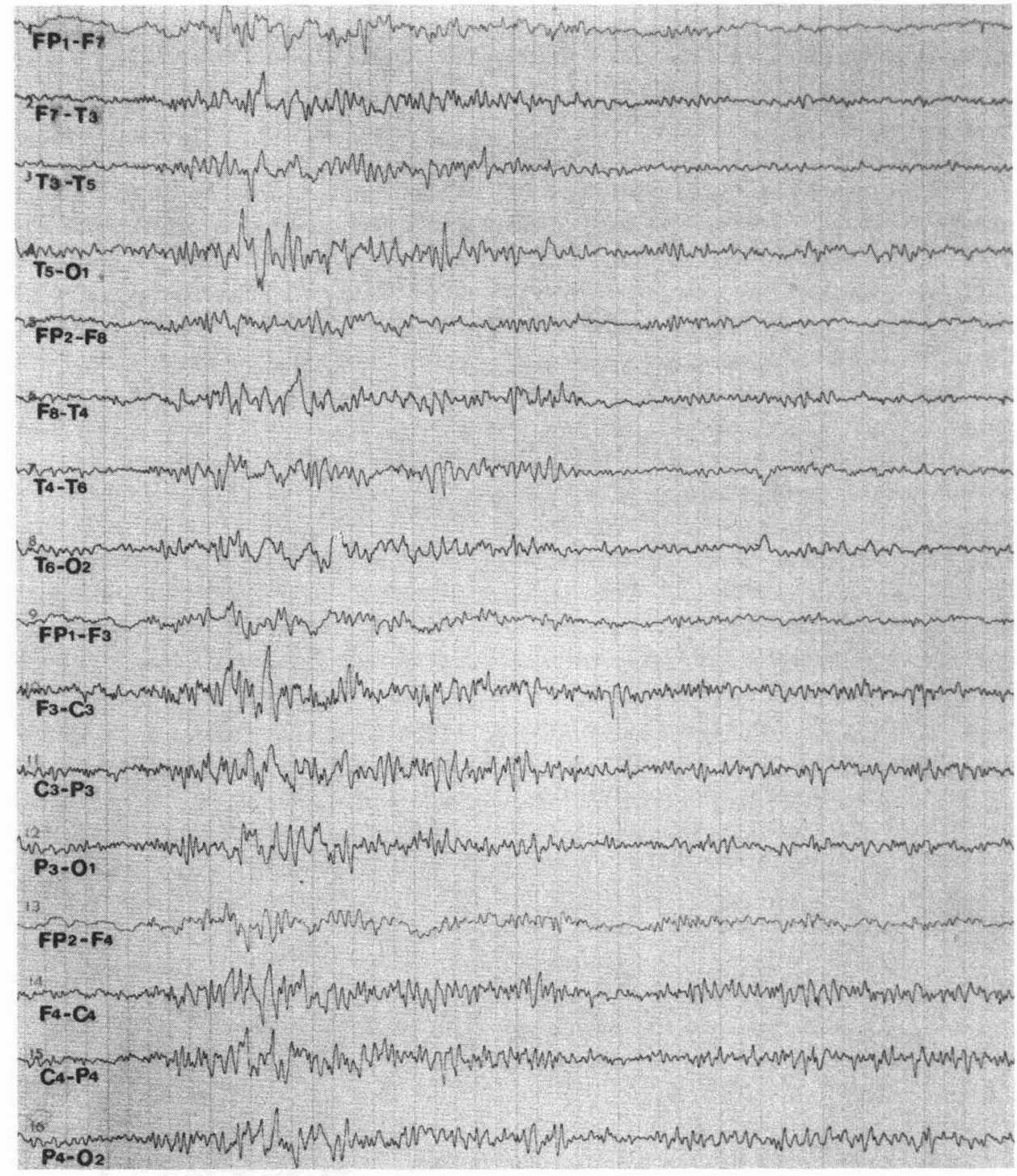

FIGURE 1. reveals beta rhythms in the background and frequent paroxysmal bursts of slow and sharp wave discharges.

system. Until recently, dopamine receptors have been categorized into $D_{1}$ and $D_{2}$ subtypes. $\mathrm{D}_{1}$ receptors are the most abundant dopaminergic receptors in the human brain. They are found in both striatal and cortico-limbic areas, and they activate adenylate cyclase and cyclic AMP. $\mathrm{D}_{2}$ receptors are found in greatest concentration in the striatum and were thought to inhibit cyclic AMP. Neuroleptic potency has been rated by the dose required to antagonize the $\mathrm{D}_{2}$ receptor. Advances in molecular 
biology have led to the cloning of genes for 2 types of $D_{1}$ and $D_{2}$ receptors $(12,13)$ and the discovery of $\mathrm{D}_{3}, \mathrm{D}_{4}$ and $\mathrm{D}_{5}$ receptors $(14,15)$. The $\mathrm{D}_{3-5}$ receptors appear to be localized primarily outside the striatum in cortical and limbic regions.

The mechanism of clozapine's clinical antipsychotic efficacy has prompted a great deal of investigation. The neuropharmacology of clozapine was recently reviewed by Baldessarini and Frankenberg (16) and Meltzer (17). Clozapine is a weak antagonist at the dopamine $\mathrm{D}_{1}$ and $\mathrm{D}_{2}$ receptors and moderate antagonist of $5 \mathrm{HT}^{2}$, $5 \mathrm{HT}^{3}$, alpha 1, alpha 2 and beta-adrenergic receptors and exhibits anticholinergic and antihistiminic properties. Recent work has pointed to $\mathrm{D}_{4}$ and $\mathrm{D}_{3}$ antagonism as the possible mediator of the antipsychotic activity of clozapine $(14,15)$. Neurophysiologic studies of clozapine indicate a preferential effect on the A10 neurons projecting to limbic areas and minimal affect on the A9 neurons projecting into the basal ganglia (18). The $\mathrm{D}_{4}$ receptor appears to be located primarily outside the striatum which could explain clozapine's lack of significant extrapyramidal effects.

\section{Dopamine and Seizures}

How dopamine antagonists induce seizures is not well understood. Some evidence points to dopamine as a regulator of seizure activity (19). The specific role which each dopamine receptor plays has yet to be fully resolved. Loscher and Czuczwar and Turski et al found that $\mathrm{D}_{2}$ agonists such as L-Dopa and the mixed $\mathrm{D}_{1}$, $\mathrm{D}_{2}$ agonist apomorphine had an anticonvulsant effect while $\mathrm{D}_{2}$ antagonists, like clozapine, tend to lower the seizure threshold $(19,20,21,22)$. These data suggest that clozapine's blockade of $\mathrm{D}_{2}$ receptors is responsible for its associated seizures but this does not explain the increased prevalence of clozapine related seizures compared to standard neuroleptics. Burke et al demonstrated the opposite effect with $\mathrm{D}_{1}$ receptor compounds (19). In his study in mice, $D_{1}$ agonists lower the seizure threshold to pilocarpine and picrotoxin and $\mathrm{D}_{1}$ antagonists exerted a protective effect against seizures. An additional mechanism is suggested by Giardino et al who reported a decrease in benzodiazepine receptor density in rat cortex after chronic clozapine administration (23), raising the possibility that clozapine could alter the seizure threshold through its effects on GABA-ergic systems.

\section{EEG Changes During Clozapine Treatment}

The patient described in this report had epileptiform discharges on her EEG following administration of clozapine. Recent studies suggest that most patients receiving clozapine have abnormal EEGs $(11,24,25)$. These changes have been reported to be dose related (26) but changes have been noted after a single dose (27). Tiihonen et al found that 16 of 16 subjects studied had profound disturbances of background activity and also paroxysms consisting of delta and theta waves, seven patients had paroxysms which were classified as epileptiform, consisting of spikes, polyspikes, or spikes and slow wave complexes (24). These findings correlate with an earlier study by Isermann and Haupt who found 26 of 36 subjects studied had 
abnormal EEGs after beginning clozapine (11). Fifteen had paroxysmal episodes of generalized slowing and 8 had epileptiform discharges. Koukkou also suggested that clozapine-induced EEG changes are associated with a better response to clozapine than those patients whose EEGs remain normal (25).

\section{Management of Clozapine-Induced Seizures}

We present this case since the management of this patient brought out a number of important points concerning clozapine-induced seizures. The group home treatment team was unfamiliar with the management of clozapine-induced seizures as evidenced by the continuation of the clozapine at the same dose after the seizure and the seven day delay in obtaining a medical evaluation.

Several recent papers comment on the management of clozapine-related seizures $(7,10,16,28,29,30)$. Prevention of seizures can be enhanced by: 1$)$ not exceeding doses of $600 \mathrm{mg} /$ day; 2) slowly increasing daily doses; and 3) avoiding concomitant use of other medications which also lower the seizure threshold. For example, lithium, neuroleptics and tricyclic antidepressants can lower the seizure threshold.

It is not known if pre-existing subclinical EEG abnormalities increase a patient's risk for seizures while on clozapine but at present, we do not recommend an EEG for all patients prior to beginning clozapine treatment. Patients with a history of seizures and/or confusional states should have a baseline EEG before starting clozapine. An EEG should also be performed on patients who have a change in mental status or seizure while on clozapine. In the case described this step should have been taken immediately after the patient had the seizure.

Subclinical EEG changes in the absence of associated clinical findings do not necessarily require an alteration in clozapine treatment. Clozapine-related seizures are not an absolute indication for discontinuation of therapy but certain steps, which were not followed in the case described, should be taken immediately after such an event. Other possible causes of seizure should be investigated. This work-up should include EEG, head CT, laboratory evaluation and possibly a neurological consultation. Following a seizure, clozapine should be held until the patient's mental state returns to baseline and then the daily dose of clozapine should be reduced. Lieberman et al suggest a $50 \%$ reduction in the daily dose (7). The manufacturer states that 31 of the 41 cases in which seizures developed remained on clozapine despite seizures. Less than $5 \%$ have had a second seizure with simultaneous treatment with valproic acid (data on file, Sandoz Pharmaceuticals, 1991). In the case presented clozapine had not yet demonstrated an antipsychotic effect and the treatment team decided to discontinue her clozapine and use carbamazepine temporarily to stabilize her mental state.

A lack of consensus exists concerning the concomitant use of anticonvulsants after a clozapine-induced seizure. If a clinician decides to use an anticonvulsant, valproic acid is the drug of choice as phenytoin may cause a decrease in clozapine plasma levels (31) and carbamazepine should be avoided due to the possibility of depressed granulocyte production. One death has been reported in a patient on 
combined treatment of clozapine and carbamazepine (data on file, Sandoz Pharmaceuticals, 1991).

Kane suggests that there may be as many as 100,000 to 200,000 schizophrenics resistant to standard neuroleptics in the U.S. (1). Currently there are approximately 23,000 individuals in the U.S. being treated with clozapine. The use of clozapine will certainly increase in the 1990's. We believe this paper addresses the important need for clinicians to continue to further their understanding of clozapine and the management of its side effects such as seizures and EEG changes.

\section{REFERENCES}

1. Kane J, Honigfeld G, Singer J, et al: Clozapine for the treatment resistant schizophrenic. Arch Gen Psych 1988; 45:789-796

2. Meltzer H, Bastani B, Young Kown K, et al: A prospective study of clozapine in treatment-resistant schizophrenic patients. Psychopharmacology 1989; 99 suppl:68-72

3. Glenenberg A, Doller J: Clozapine versus chlorpromazine for the treatment of schizophrenia: Preliminary results double-blind study. J Clin Psychiatry 1979; 40:238-240

4. Panteleeva G, Lovskaya M, Belyaev B, et al: Clozapine in the treatment of schizophrenic patients: An international multicentered trial. Clin Therapy 1987; 10(1):57-68

5. Lindstrom L: The effect of long-term treatment with clozapine in schizophrenia: A retrospective study in 96 patients treated with clozapine for up to 13 years. Acta Psychiatr Scand 1988; 77:524-529

6. Casey D: Clozapine: Neuroleptic-induced EPS and tardive dyskinesia. Psychopharmacology 1989; 99 suppl:47-53

7. Lieberman J, Kane J, Celeste J: Clozapine guidelines for clinical management. J Clin Psychiatry 1989; 50:329-338

8. Logothetis J: Spontaneous epileptic seizures and electroencephalographic changes in the course of phenothiazine resistant schizophrenic. Arch Gen Psych 1988; 45:789-796

9. Sandoz, Inc. Clozaril (clozapine): The atypical antipsychotic. East Hanover, NJ. Sandoz Pharmaceuticals Corp., 1990

10. Devinsky O, Honigfeld G, Patin J: Clozapine-related seizures. Neurology 1991; 41:369-371

11. Iserman $\mathrm{H}$, Haupt R: Auffallige EEG-veranderungen unter clozapin-behandlung bei paranoid-halluzinatorischen psychosen. Der Nervenarzt 1979; 47:268

12. Tiberi M, Jarvie KR, Silvia C, et al: Cloning, molecular characterization and chromosomal assignment of a gene coding a second D1 dopamine receptor subtype: differential expression pattern in rat brain compared with the D1A receptor. Proc Natl Acad Sci 1991; 88:7491-7495

13. Grandy DK, Marchionni MA, Makam H, et al: Cloning of the cDna and gene for a human D2 receptor. Proc Natl Acad Sci 1989; 86:9762-9766

14. Sokoloff P, Giros B, Martres M, et al: Molecular cloning and characterization of a novel dopamine receptor (D3) as a target for neuroleptics. Nature 1990; 347:146-151

15. Van Tol H, Bounzow J, Guan H, et al: Cloning of the gene for a human dopamine D4 receptor with high affinity for the antipsychotic clozapine. Nature 1991; 350:610-614

16. Baldessarini R, Frankenburg F: Clozapine: A novel antipsychotic agent. NEJM 1991; 324(11):746-754

17. Meltzer H: The mechanism of action of novel antipsychotic drugs. Schizophrenia Bull $1991 ; 17(2): 263-287$ 
18. Hand T, Hu X, Wang R: Differential effects of acute clozapine and haloperidol on the activity of ventral tegmental (A10) and nigrostriatal (A9) dopamine neurons. Brain Res 1987; 414:257-269

19. Burke K, Chandler C, Starr B, et al: Seizure promotion and protection by $\mathrm{D}_{1}$ and $\mathrm{D}_{2}$ dopaminergic drugs in the mouse. Pharm Biochem and Behavior 1990; 36:729-733

20. Turski L, Cavalheiro E, Bortolotto Z, et al: Dopamine-sensitive anti-convulsant site in the rat striatum. J of Neuroscience 1988; 8(11):4027-4037

21. Loscher W, Czuczwar S: Studies on the involvement of dopamine D1 and D2 receptors in the anticonvulsant effects of dopamine agonists in various rodent models of epilepsy. Eur J of Pharmacol 1986; 128:55-6

22. Al-Tajir G, Starr M, Chandler et al: Opposing effects of dopamine $D_{1}$ and $D_{2}$ receptor stimulation on the propagation of motor seizures in mice and rats. $\mathrm{Br} \mathrm{J}$ of Pharmacol 1990; 99:261P

23. Giardino L, Calza L, Piazza PV, Amato G: Multiple neurochemical action of clozapine: a quantitative autoradiographic study of DA2, opiate and benzodiazepine receptors in the rat brain and after long-term treatment. J of Neural Transmission 1991; 83:189-203

24. Tiihonen J, Nousiainen U, Hakola P, et al: EEG abnormalities associated with clozapine treatment. Am J Psychiatry 1991; 148(10):1406

25. Koukkou M, Angst J, Zimmer D: Paroxysmal EEG activity and psychopathology during treatment with clozapine. Pharmacopsychiatry 1979; 12:173-183

26. Leppig M, Bosch B, Naber D: Clozapine in the treatment of 121 out-patients. Psychopharmacology 1989; 99 suppl:77-79

27. Roubicek J, Major I: EEG profile and behavioral changes after a single dose of clozepine in normals and schizophrenics. Bio Psychiatry 1977; 12:613-633

28. Haller E, Binder R: Clozapine and seizures. Am J Psychiatry 1990; 147(8):1069-1071

29. Baker R, Conley R: Seizures during clozapine therapy. Am J Psychiatry 1991; 148(9): $1265-66$

30. Safferman A, Lieberman J, Kane J, et al: Update on the clinical efficacy and side effects of clozapine. Schizophrenia Bull 1991; 17(2):248-263

31. Miller D: Effects of phenytoin on the plasma clozapine levels in two patients. J Clin Psychiatry 1991; 52:23-25 